\title{
REVISTA \\ EUROLATINOAMERICANA DE \\ DERECHO ADMINISTRATIVO
}

VOL. 5 | N. 1 | ENERO/ JUNIO 2018 | ISSN 2362-583X

SANTA FE | ARGENTINA | PERIODICIDAD SEMESTRAL

Revista oficial de la Red Docente Eurolatinoamericana de Derecho Administrativo

formada por las siguientes instituciones:
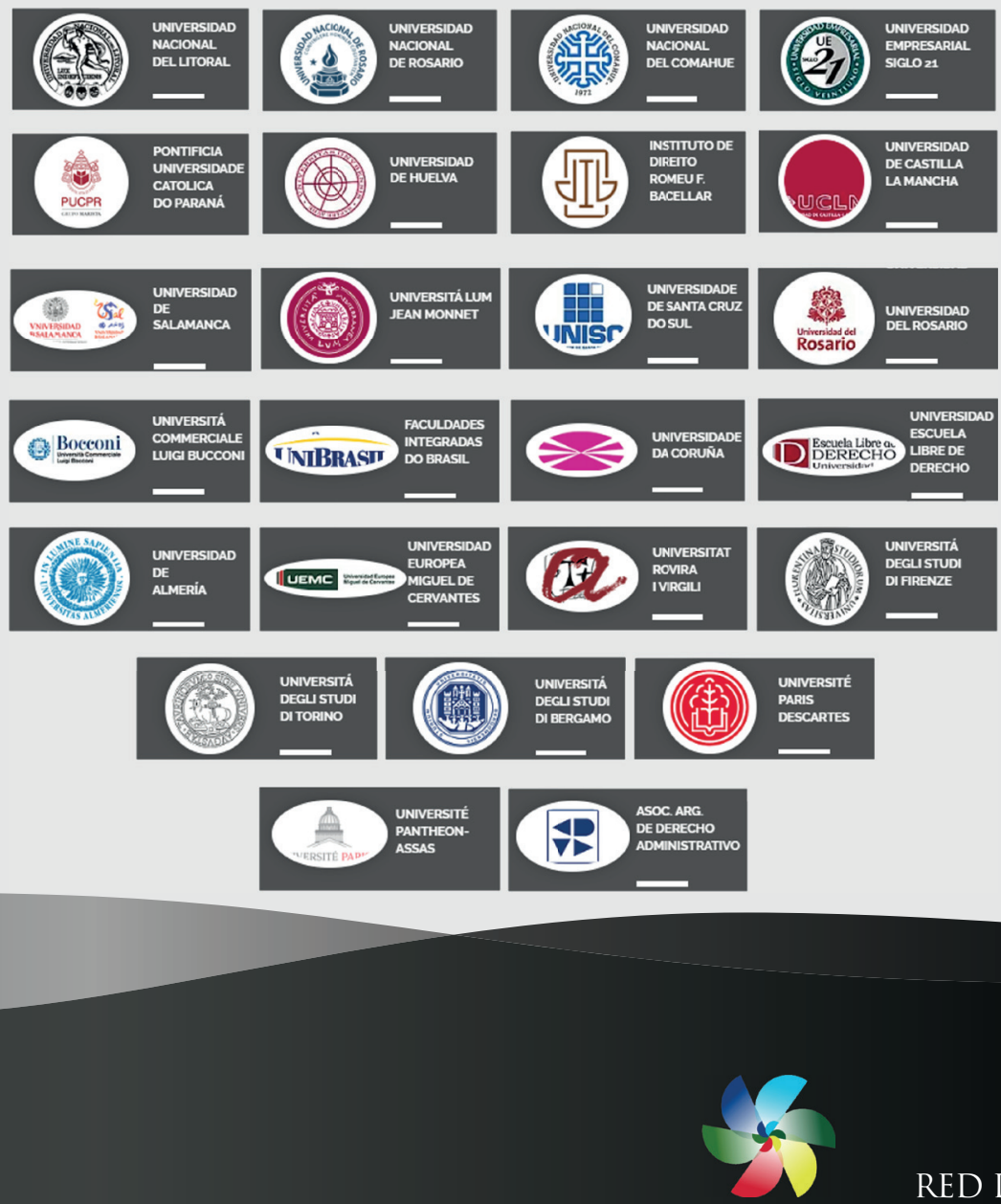

RED DOCENTE

EUROLATINOAMERICANA DE DERECHO ADMINISTRATIVO 


\title{
Servicio público como política en materia de derechos fundamentales: implicancias
}

\author{
Public service as a policy in the field of fundamental rights: \\ implications
}

\author{
MIGUEL ANGEL ARRÚA GOBOI," \\ I Universidad Nacional del Litoral (Santa Fe, Argentina) \\ miguelarruagobo@gmail.com \\ Recibido el/Received: 09.07.2019 / July 09th, 2019 \\ Aprobado el/Approved: 02.10.2019/ October 2nd, 2019
}

\section{RESUMEN:}

Una de las construcciones jurídicas que ha tenido mayor evolución, divergencias conceptuales y de contenido, ha sido y es la del Servicio Público, principalmente por su particular inclusión en las teorías sobre el Estado pero también por su alcance como herramienta de garantía de los derechos humanos, dada la evolución operada por el Derecho Administrativo y la generación de espacios de convergencia normativa que exigen respuestas distintas de las ensayadas en el siglo pasado. En este artículo se abordará someramente la transformación de la noción de Servicio Público desde la óptica de los derechos fundamentales, su inclusión en tipologías elaboradas por la doctrina y las implicancias de una esquematización que, al influjo de los desarrollos convencionales que forman parte del bloque de juridicidad existente y

\section{ABSTRACT:}

One of the legal constructions that has had the most evolution, conceptual and content divergences, has been and is that of the Public Service, mainly because of its particular inclusion in the theories about the State but also because of its scope as a guarantee tool for human rights. , given the evolution of Administrative Law and the generation of regulatory convergence spaces that require answers different from those tested in the last century. This article will briefly address the transformation of the notion of Public Service from the perspective of fundamental rights, its inclusion in typologies elaborated by the doctrine and the implications of a schematization that, under the influence of conventional developments that are part of the block of existing juridicity and doctrinaire interpretation, decant in a proposal closely related to the application -in this field- of

Como citar este artículo | How to cite this article: ARRÚA GOBO, Miguel Angel. Servicio público como política en materia de derechos fundamentales: implicancias. Revista Eurolatinoamericana de Derecho Administrativo, Santa Fe, vol. 5, n. 1, p. 6983, ene./jun. 2018. DOI: 10.14409/redoeda.v5i1.8858

*Doctorando en Derecho, Universidad Nacional del Litoral (Santa Fe, Argentina). Miembro del Grupo de Coordinación Docente de la Especialización en Derecho Administrativo. Especialista en Derecho Administrativo (UNL), Especialista en Asesoramiento Jurídico del Estado (ECAE-PTN), Especialista en Derecho Notarial (UNL), Abogado (UNL), Miembro de Grupos de Investigación en la Facultad de Ciencias Jurídicas y Sociales de la Universidad Nacional del Litoral, Miembro de la Asociación Argentina de Derecho Administrativo, del Foro de Jóvenes Administrativistas, y la Asociación Entrerriana de Derecho Administrativo. Director General de Asuntos Jurídicos del Ministerio de Gobierno y Justicia de la Provincia de Entre Ríos. Autor de diversas publicaciones en su especialidad y disertante en congresos afines a la misma. 
la interpretación doctrinaria, decante en una propuesta relacionada íntimamente con la aplicación -en este campo- del principio de actuación conjunta como técnica de garantía de las prerrogativas comprometidas en la figura analizada, encontrándose aquí un terreno fértil para el desarrollo de tal precepto.

Palabras clave: servicio público; Estado; derecho administrativo; derechos fundamentales; dignidad. the principle of joint action as a guarantee technique of the prerogatives committed in the analyzed figure, being here a fertile ground for the development of such precept.

Keywords: public service; state; administrative law; fundamental rights; dignity.

\section{SUMARIO:}

1. Introducción. Aproximaciones a la noción de servicio público. 2. El impacto del advenimiento del nuevo modelo de estado en la configuracion del servicio publico. $\mathbf{3}$. El servicio público en el marco constitucional y de los ordenamientos internacionales de derechos humanos. 4. Un servicio público "al verdadero servicio" del ser humano individual y colectivamente considerado. 5. Conclusión. Conexidad multidimensional del servicio publico como derecho fundamental y verdadera política pública. 6 . Referencias.

\section{INTRODUCCIÓN. APROXIMACIONES A LA NOCIÓN DE SER- VICIO PÚBLICO.}

El concepto de servicio público ha atravesado en la historia de nuestro país varias etapas signadas por un fuerte rasgo de índole sociopolítica, en virtud de su relación con la teoría del Estado, la vinculación de éste con la sociedad, su función de garantía de los Derechos Humanos y la definición como categoría jurídica administrativa.

La evolución en la construcción de la noción de servicio público, desde su vertiente subjetiva hasta una marcada objetivización enfocada en la actividad, desemboca en estudios (sobre todo los autores italianos Caia, Manzzarolli, Cammeli) que se enrolan en el examen de la técnica de organización de las actividades económicas entendidas como socialmente esenciales.

El destacado Meilán Gil, abordando la implicancia del servicio público en el esquema moderno, enseña que “Lo característico del servicio público como categoría jurídica diferenciada es su configuración como título habilitante de potestades administrativas, o justificación de la acción del poder público en general si se prefiere. ${ }^{1}$

Esa habilitación no escapa al juego de las disposiciones contenidas en las Constituciones, Tratados Internacionales y demás instrumentos que indudablemente conforman el bloque de juridicidad de los Estados.

Reconocemos que el modelo de servicio público en Argentina ostenta una particular autonomía en orden a las supuestas influencias europeas y angloamericanas que

1 MEILÁN GIL, José Luis. El servicio público en el derecho actual. Anuario da Facultade de Direito da Universidade da Coruña, La Coruña, España, № 01, p. 371, Año 1997.- 
parte de la doctrina atribuye como condicionantes en su evolución. Esas influencias responden a dos modos de comprender el interés general, categoría de difícil elaboración de por sí: en las ideas europeas se desarrolla la noción de "interés público", conectado a la idea de Nación, distintivo y superior de los intereses privados, que debe ser definido y gestionado por un ente diferente a éstos: la autoridad pública. En el pensamiento angloamericano, por el contrario, campea el "interés común": la satisfacción de los clientes del servicio y la comunidad en general, más allá del cumplimiento del interés particular.

Tales ideas no podrían pregonarse en el caso argentino, donde desde la sanción de la Constitución Nacional de 1853, se englobaba prácticamente la totalidad de las funciones administrativas a cargo del Estado Nacional, en un concepto amplio que distaba de los razonamientos esbozados en el párrafo precedente. Ello sin perjuicio de reconocer que ya en las Asambleas Constituyentes de 1813 y 1826 se empleó el término con esa magnitud, más allá de la utilización estricta para identificar las actividades económicas consideradas públicas.

En esta aproximación no podemos dejar de mencionar que, para la teoría del Estado, el servicio público implica una forma específica de intervención estatal en la economía, cuya manifestación genérica es el denominado poder de policía y, con mayor precisión, el poder de policía de prosperidad que incluye acciones de prestación y fomento destinadas a la consecución del bienestar material de los ciudadanos. Así, en el Artículo $75^{\circ}$ inciso $18^{\circ}$ de nuestra Constitución Nacional se establece, dentro de la competencia del Congreso, la de proveer lo conducente a la prosperidad del país, al adelanto y bienestar de todas las provincias, y al progreso de la ilustración, dictando planes de instrucción general y universitaria, y promoviendo la industria, la inmigración, la construcción de ferrocarriles y canales navegables, la colonización de tierras de propiedad nacional, la introducción y establecimiento de nuevas industrias, la importación de capitales extranjeros y la exploración de los ríos interiores, por leyes protectoras de estos fines y por concesiones temporales, de privilegios y recompensas de estímulo. El Artículo $125^{\circ}$, referido a las provincias, las faculta a celebrar tratados parciales para fines de administración de justicia, de intereses económicos y trabajos de utilidad común, con conocimiento del Congreso Federal; y promover su industria, la inmigración, la construcción de ferrocarriles y canales navegables, la colonización de tierras de propiedad provincial, la introducción y establecimiento de nuevas industrias, la importación de capitales extranjeros y la exploración de sus ríos, por leyes protectoras de estos fines, y con sus recursos propios.

Teniendo en cuenta la variedad de elementos que confluyen en la configuración de esta idea, el Profesor González Moras lo ha discernido poniendo el acento en el componente económico de la actividad, la obligatoriedad de prestación por parte del Estado o sujetos particulares habilitados, el régimen de derecho público, la subordinación al cumplimiento efectivo de los derechos y garantías que se reconocen en los Artículos 
42 y 43 de la Constitución Nacional, y la continuidad en su desarrollo, además de la finalidad de "...satisfacer necesidades materiales que por su incidencia económica o social se constituyan en medio para alcanzar el bienestar general de la colectividad, y cuyo sujeto acreedor es el usuario actual o potencial del mismo, en su calidad de contribuyente del erario público."2.

\section{EL IMPACTO DEL ADVENIMIENTO DEL NUEVO MODELO DE ESTADO EN LA CONFIGURACION DEL SERVICIO PUBLICO}

En la evolución a la que asistimos producto del influjo del bloque de convencionalidad y nuevas formas de integración en el marco del Estado Constitucional de Derecho, y dadas las implicancias que conllevan los nuevos fenómenos a los que se deberá atender, es claro que el Derecho Administrativo “...se mueve entre la atribución de potestades y la limitación de las mismas" 3 . Su concepción originaria sigue siendo “...la defensa del derecho individual frente a la actuación administrativa." 4.

El gran desafío pasa hoy por un ordenamiento conformador de la sociedad, dada la actual crisis en la escala de valores. Para ello es menester la existencia de un pensamiento abierto, situándonos en el contexto en el cual nos encontramos para poder comprender profundamente al Derecho Administrativo Moderno. La Administración Pública comenzó con el interés general de administrar, éste interés que debemos destacar es un producto cultural que se exhibe necesariamente como concreto y racionalizado.

El profesor Schimdt-Assman, al analizar los distintos factores interactuantes en las transformaciones de esta rama, califica como estrictamente jurídica a la contribución de la jurisprudencia, afirmando en cambio que la doctrina requiere "...cierta distancia y perspectiva respecto de los sucesos cotidianos"5 a diferencia de los factores anteriores, o sea abstraerse de lo relacionado a los intereses particulares que pueden presentarse; además un conocimiento profundo de parte general y especial del Derecho Administrativo, trabajando junto a la dogmática para detectar puntos críticos y alternativas de solución.

Destaco como notas salientes o ejes los siguientes:

2 GONZÁLEZ MORAS, Juan M.. El concepto de servicio público. Revista Argentina del Régimen de la Administración Pública, Buenos Aires, Año XXVI - 309, p. 185 y ss., Ediciones RAP SA, 2004.

3 VILLAR PALASI-VILLAR EZCURRA. El ordenamiento jurídico administrativo. Principios de Derecho Administrativo, Madrid, Tomo I, p. 14 Editorial Universidad Complutense de Madrid, Facultad de Derecho, 1987.

4 VILLAR PALASI-VILLAR EZCURRA: El ordenamiento jurídico administrativo. Principios de Derecho Administrativo, Madrid, Tomo I, p. 15. Editorial Universidad Complutense de Madrid, Facultad de Derecho, 1987.

5 SCHIMDT-ASSMAN, Eberhard. La necesidad de la reforma en el derecho administrativo. En: BARNES, Javier (Editor) Innovación y reforma en el Derecho Administrativo, Madrid, p. 31, Editores INAP y Derecho Global, 2012. 
a) Búsqueda de una mayor participación del Estado en la protección directa de los derechos de la comunidades, ya que en el Derecho Administrativo se hallan finalmente los límites verdaderos en el respeto a los derechos fundamentales y a los principios generales de legalidad, prohibición de arbitrariedad, objetividad, etc.

b) Aparición del concepto de "gobernanza", vinculado al de buen gobierno y buena administración, con el objetivo de alcanzar un alto grado de eficacia en la toma de decisiones y aumentar la participación de actores políticos, sociales y económicos a fin de legitimar las decisiones de la Administración, en un contexto con influencia de las nuevas tecnologías y la globalización. Debe ser un Derecho Administrativo integrador, mutable, multidimensional, interactivo, difuso, plural, asociativo y progresivo. Se vislumbra una expansión de su ámbito de aplicación, estableciendo COMO ADMINISTRAR Y QUIENES PARTICIPAN DE ELLO. Cobran destacada importancia conceptos cuya práctica no es novedosa, como la descentralización o la horizontalidad, el dinamismo en los procesos, la flexibilidad normativa y el flujo de información constante.

c) Introducción creciente de la cuestión ética en el campo del Derecho Administrativo, a través de las normas de conducta impuestas tanto en el orden interno como el internacional, y un vigoroso control social.

d) Incidencia del fenómeno de la globalización, que requiere la adopción de reglas comunes e integradoras, llevando a que el Derecho Administrativo pierda su condición interna para expandirse conforme se amplían los límites del mercado mundial y la complejidad en las relaciones interregionales. Así se da origen al denominado Derecho Administrativo Global, determinado por el vasto incremento del alcance y formas de la regulación transgubernamental y de la interdependencia resultante de la globalización en áreas tales como la bancaria y financiera.

e) Desarrollo concreto de la noción de "gobierno electrónico", no sólo como nueva forma de descentralización operativa extendida a la gestión y su relación con el ciudadano, sino también como un proceso de automatización de las decisiones. Esta modalidad requiere el marco normativo necesario para su propia seguridad, para la transparencia de los procesos involucrados y la superación de los arcaicos métodos que caracterizan a la burocracia del Siglo XX actualmente persistente. El procedimiento moderno se concibe, al decir de Barnes, como“....instrumento que acompaña el ciclo completo de la política pública".6

6BARNES, Javier: (Editor) Innovación y reforma en el Derecho Administrativo, Madrid, p. 375, Editores INAP y Derecho Global, 2012. 
f) Como eje centralizador de los anteriores, el reconocimiento de la primacía del ser humano y su dignidad, dirigiendo la actividad administrativa al cumplimiento del bienestar común, la protección y concreción efectiva y eficaz de los derechos fundamentales.

Se aprecia una marcada subjetivización, individualización y sensibilización de esta rama, como efecto de que el "individuo" como sujeto de derechos sea ahora el centro de atención.

Los objetivos fundamentales para el moderno Estado de Derecho, impregnado de estas notas, serán la ordenación de complejas contraposiciones de intereses; el hallazgo de modelos de procedimientos y de organizaciones adecuadas para adaptarse a tales situaciones. ${ }^{7}$.

La adecuada selección de los "ámbitos de referencia" y el estudio de sus orígenes, factores condicionantes y características, posibilitará concluir sobre la factibilidad de incorporarlos a la teoría general del Derecho Administrativo, en continua interacción con la realidad social que aporta el sustrato de su contenido.

El Estado tiene como función primaria o genérica la promoción de la dignidad humana, lo que lleva a entender sin esfuerzo que el bienestar de los ciudadanos debe ocupar un lugar absolutamente prioritario en la actividad del Estado. Como bien enseña el maestro Rodríguez-Arana Muñoz, “la garantía del interés general es la principal tarea del Estado, y por ello el Derecho Administrativo ha de tener presente esta realidad y adecuarse institucionalmente a los nuevos tiempos, pues, de lo contrario perderá la ocasión de cumplir la función que lo justifica, cual es la mejor ordenación y gestión de la actividad pública con arreglo a la justicia".8

Por lo tanto todas las decisiones del Estado, a través de sus órganos administrativos deben respetar la razonabilidad. A través del pensamiento plural, dinámico, complementario, el Derecho Administrativo procurará la consecución de la mejora del nivel de vida de los ciudadanos, utilizando el Poder Público del cual se encuentra investido para proteger y al mismo tiempo incentivar la participación de las libertades individuales en el marco de los derechos fundamentales de la comunidad.

El Derecho Administrativo de nuestro tiempo se encuentra signado por grandes desafíos. La irrupción de los fenómenos de globalización, integración regional, tecnificación, exigen que se adopten parámetros normativos comunes y respetuosos de los derechos consagrados en los distintos instrumentos internacionales. La vinculación entre los Estados ha alcanzado ribetes inimaginables en épocas pasadas y ya no puede

7 SCHMIDT-ASSMAN, Eberhard: La necesidad de la reforma en el derecho administrativo. En: BARNES, Javier (Editor) Innovación y reforma en el Derecho Administrativo, Madrid, p. 63, Editores INAP y Derecho Global, 2012.

8 RODRÍGUEZ-ARANA MUÑOZ, Jaime. Derecho Administrativo Español, Tomo I, México, Ed. Porrúa, 2005, p. 39.- 
pensarse en esta rama como desvinculada de los grandes acontecimientos mundiales. Los problemas para resolver han dejado de ser propios de un Estado determinado y urgen soluciones que deberían generarse en el seno de acuerdos internacionales, interregionales, sin dejar de atender a la idiosincrasia de cada país. Aquellos valores superiores que el orden jurídico tiende a proteger, guían la creación de herramientas que posibiliten al ciudadano ejercer sus derechos y hacer valer sus garantías sin que la Administración sea una mera observadora o fiscalizadora, sino que debe buscarse una participación intersectorial para que el cumplimiento de esas finalidades resulte del compromiso común de los actores del nuevo orden mundial.

Vértice orientador del nuevo paradigma lo conforma la Constitución y la consagración del principio de actuación conjunta. No olvidar que la llamada concretización o implementación constitucional no puede limitarse a una "...deducción mecánica de conocimientos desde la Constitución"9. Debe ir más allá, reconociendo los continuos cambios en los procesos. Aquí no es menor la histórica presencia de la burocracia, cuya estructura resistente a las más variadas críticas, configura uno de los puntos de partida para la implementación de la que doctrinariamente se habla. A nivel estadual se poseen normas con aspiraciones de avanzadas pero que al momento de su concreción chocan con el aparato existente, forjado al calor de las viejas disputas entre el sector privado y el público.

Específicamente en lo concerniente a la conceptualización y caracterización del servicio público bajo el paradigma del moderno Derecho Administrativo, resulta imperioso reconocer y desandar el andamiaje propuesto por la aplicación del mentado principio de actuación conjunta, que justamente responde a la configuración multiforme del espacio administrativo global.

\section{EL SERVICIO PÚBLICO EN EL MARCO CONSTITUCIONAL Y DE LOS ORDENAMIENTOS INTERNACIONALES DE DERECHOS HUMANOS}

La amplitud del concepto de servicio público en nuestro país se cristalizó ya en los Tratados Internacionales suscriptos por la Confederación Argentina, por ejemplo la Ley No 55, del 27 de septiembre de 1855 que aprobó el "Tratado de amistad, comercio y navegación con Chile"; la Ley № 102, del 26 de septiembre de 1856, aprobatoria del "Tratado de paz, amistad, comercio y navegación con Paraguay"; la Ley № 210, del 13 de julio de 1859, aprobatoria del "Tratado de paz, amistad, comercio y navegación con

\footnotetext{
9 SCHIMDT-ASSMAN, Eberhard: La necesidad de la reforma en el derecho administrativo. En: BARNES, Javier (Editor) Innovación y reforma en el Derecho Administrativo, Madrid, p. 53, Editores INAP y Derecho Global, 2012.
} 
Bolivia"; y la Ley № 771, del $1^{\circ}$ de julio de 1876, aprobatoria del "Tratado de amistad, comercio y navegación con Paraguay".

La reforma constitucional de 1949 provoca cambios sustanciales en el concepto de servicio público al incluirse éste en el sistema de derechos y garantías constitucionales. En la parte dogmática ("Principios Fundamentales"), el Capítulo IV sobre "La función social de la propiedad, el capital y la actividad económica", incorporaba el Artículo $40^{\circ}$ en estos términos: "....Los servicios públicos pertenecen originariamente al Estado y bajo ningún concepto podrán ser enajenados o concedidos para su explotación. Los que se hallaren en poder de particulares serán transferidos al Estado, mediante compra o expropiación con indemnización previa, cuando una ley nacional lo determine...."

Dicha mención es importante, ya que, no obstante el devenir histórico que produjo el retorno al texto de 1853, la reforma de 1994 añade entre otros, el Artículo 42 , el que, dentro del capítulo "Nuevos derechos y garantías", marca un regreso a los postulados de 1949 (servicio público como derecho y garantía de los particulares) y dinamiza los fundamentos del servicio público al incorporar al "usuario" como sujeto privilegiado de este régimen. Ese artículo es calificado por la doctrina como un mínimo común denominador en torno a los caracteres típicos del servicio público: a) obligatoriedad; b) continuidad; c) regularidad; d) universalidad y uniformidad. Ese mínimo refiere a una serie de derechos específicos que deben garantizarse a los usuarios, en los marcos regulatorios de cada servicio: la protección de la salud, seguridad e intereses económicos; la información adecuada y veraz; la libertad de elección; condiciones de trato equitativo y digno; la educación para el consumo; la defensa de la competencia contra toda forma de distorsión de los mercados; el control de los monopolios naturales y legales; la calidad y eficiencia de los servicios públicos; la constitución de asociaciones de consumidores y de usuarios; la participación de las asociaciones de consumidores y usuarios en los organismos de control.

Por ende, el servicio público, en general y en nuestro marco constitucional, es entendible como técnica de intervención estatal en la economía, en el sistema de potestades (Art. $75^{\circ}$ inc. 18 y 23), y como garantía sustancial y adjetiva propia del sistema de derechos y garantías constitucionales (Arts. $42^{\circ}$ y $43^{\circ}$ ) a favor de los ciudadanos en su calidad de usuarios. A esa garantía constitucional se hallan subordinados el derecho de la competencia y la defensa del consumidor.

A nivel de derecho internacional, y reconociendo que en todas sus variables el servicio público es regulado10, me detendré en un breve análisis de los instrumentos del derecho internacional de los derechos humanos por su directa vinculación con la temática escogida para el trabajo, ya que coloca como centro del régimen al usuario

10 GONZÁLEZ MORAS, Juan M.. El concepto de servicio público en los Ordenamientos Públicos Globales. Revista Argentina del Régimen de la Administración Pública, Buenos Aires, №361, p. 395.- 
operando de esta manera como un contrapeso a la legislación del comercio y de la integración comunitaria.

Así, la Declaración Americana de Derechos y Deberes del Hombre (1948) en su Capítulo Segundo (Deberes), determina: "Toda persona tiene el deber de pagar los impuestos establecidos por la Ley para el sostenimiento de los servicios públicos."11. La Convención Americana sobre Derechos Humanos (Pacto de San José de Costa Rica) establece en su Primera Parte una obligación para los Estados Partes de respetar los derechos y libertades reconocidos en aquélla, y a garantizar su "...libre y pleno ejercicio a toda persona que esté sujeta a su jurisdicción...", además de un deber de adoptar medidas necesarias para hacer efectivos tales derechos y libertades, en caso que ya no estuvieran incorporados a los respectivos ordenamientos. Lo cual se enraiza con la igualdad ante la ley plasmada dentro del Capítulo relativo a los Derechos Civiles y Políticos ${ }^{12}$. El Protocolo adicional a la Convención Americana sobre Derechos Humanos en materia de derechos económicos, sociales y culturales "Protocolo de San Salvador" añade "Toda persona tiene derecho a vivir en un medio ambiente sano y a contar con servicios públicos básicos." 13 . La Declaración Universal de Derechos Humanos consagra el derecho de toda persona a "...un nivel de vida adecuado que le asegure, así como a su familia, la salud y el bienestar, y en especial la alimentación, el vestido, la vivienda, la asistencia médica y los servicios sociales necesarios..."14. Asimismo, la "Convención sobre la Eliminación de todas las formas de Discriminación contra la Mujer", dentro de las medidas que se estiman adecuadas para asegurar la efectividad del derecho a trabajar, enumera la de "Alentar el suministro de los servicios sociales de apoyo necesarios para permitir que los padres combinen las obligaciones para con la familia con las responsabilidades del trabajo y la participación en la vida pública, especialmente mediante el fomento de la creación y desarrollo de una red de servicios destinados al cuidado del los niños..."15, agregando en lo referente al desarrollo rural, el aseguramiento del derecho al goce de condiciones de vida adecuadas, específicamente en materia de vivienda, servicios sanitarios, electricidad, agua, transporte y comunicaciones ${ }^{16}$. La "Convención Internacional sobre la Eliminación de todas las formas de Discriminación Racial" fija el compromiso de los Estados Partes, de garantizar el derecho de toda persona a la igualdad ante la ley, sin distinción de raza, color u origen nacional o étnico, particularmente en el goce de

\footnotetext{
11 Declaración Americana de Derechos y Deberes del Hombre, Artículo XXXVI.-

12 Convención Americana sobre Derechos Humanos, Arts. 1.1, 2 y 24.-

13 Protocolo adicional a la Convención Americana sobre Derechos Humanos en materia de derechos económicos, sociales y culturales "Protocolo de San Salvador", Art. 11.1.-

14 Declaración Universal de Derechos Humanos, Artículo $25^{\circ}$ inciso 1.-

15 Convención sobre la Eliminación de todas las formas de Discriminación contra la Mujer, Art. $11^{\circ}$ inc. 2 apartado c).

16 Ídem, Artículo $14^{\circ}$ inciso 2) apartado h.-
} 
los derechos económicos, sociales y culturales, concretamente el derecho a la salud pública, la asistencia médica, la seguridad social y los servicios sociales y el acceso a todos los lugares y servicios destinados al uso público ${ }^{17}$. La Convención sobre los Derechos del Niño, plasma el reconocimiento del derecho al disfrute del más alto nivel posible de salud y a servicios para el tratamiento de las enfermedades y la rehabilitación de la salud 18 .

En todos estos instrumentos encontramos la expresa referencia a los servicios públicos, identificados como "servicios sociales" en una noción más general. El problema concreto se da en torno a la operatividad de tales derechos ya que el compromiso de los Estados firmantes incluye la adaptación de su derecho interno y planes de gobierno orientados a la efectivización de las garantías propugnadas. Ya sea en los casos en que se posee acción directa como en los que se requiere el dictado de otras normas, el obstáculo frecuente es la dilación en los poderes del Estado, abriendo el espacio a que las decisiones jurisdiccionales tomen el protagonismo en dicho sentido. Ello sin olvidar el juego de las garantías como núcleo mínimo de estos derechos cuyo respeto y afianzamiento es de cumplimiento ineludible por los Estados.

\section{UN SERVICIO PUBLICO "AL VERDADERO SERVICIO" DEL SER HUMANO INDIVIDUAL Y COLECTIVAMENTE CONSIDERADO}

Actualmente, el servicio público se desenvuelve en un contexto que tiende a segmentar los mercados y a generar la máxima libertad compatible con la calidad y eficiencia de las actividades; objetivos que en el caso argentino se transformaron en un deber estatal conforme al Artículo 42 de la Constitución Nacional. 19

La mirada de los Constituyentes de 1853 sobre el Estado, el ordenamiento jurídico preexistente y la concepción de la titularidad estatal del servicio público, brindó a esta figura una construcción autónoma, diferencial de otros regímenes y que se fue modulando por el sistema de derechos humanos.

Pérez Hualde, a mi criterio en un intento de incluir en la conceptualización del servicio público la impronta de los factores que subyacen en su estructura y objetivos, lo ha definido como "...el régimen exorbitante impuesto por el legislador, y garantizado por las autoridades, a una actividad económica determinada, sustrayéndola -en la medida necesaria- de las reglas de la libertad de mercado con la finalidad fundada y motivada

\footnotetext{
17 Convención Internacional sobre la Eliminación de todas las formas de Discriminación Racial Artículo $5^{\circ}$, incisos e) apartado iv y f).-

${ }^{18}$ Convención sobre los Derechos del Niño, Artículo $24^{\circ}$.-

19 IVANEGA Miriam M.. Urbanismo y Servicios Públicos. Biblioteca Jurídica Virtual del Instituto de Investigaciones Jurídicas UNAM, México, p. 205, Año 2011.
} 
de asegurar el bienestar general mediante su satisfacción a la generalidad de la comunidad en ejercicio de potestades constitucionales" 20.

Traigo a colación la clasificación que da Laporta sobre los derechos sociales, distinguiéndolos en cuatro grupos: el primero integrado por las llamadas "libertades", derechos que implican la protección normativa de un ámbito de acción frente a las interferencias del Estado o de los particulares. El segundo, que abarca los "derechos de prestación", en los cuales se posee un título para que se entreguen bienes, o presten servicios o se asignen fondos o recursos para vivienda, salud, pensión o educación. En el tercer grupo encontramos los derechos a ciertas posiciones o status legales, por ejemplo el derecho a un empleo, o tener status como el de jubilado, huérfano, viuda, que a su vez provoca el acceso a ciertas prestaciones, beneficios o exenciones. En el último grupo se hallan los derechos a bienes públicos, que significan aspiraciones a la existencia de estados de cosas buenos o deseables (progreso científico, medio ambiente limpio). El autor mencionado indica que, dada esta diferenciación, los derechos sociales fundamentales los encontraríamos, sobre todo de entre los derechos de prestación y los derechos a ciertas posiciones o status legales 21 .

En esa línea podemos inferir que la adecuada, eficaz y eficiente prestación de los servicios públicos en la actualidad se encuentra emparentada directamente con la satisfacción del fin último del ordenamiento administrativo e involucra a todos los niveles de actuación. Ya se ha sostenido que los derechos fundamentales sociales "se refieren a determinadas acciones del Estado, de los Poderes públicos, que hacen directa y esencialmente a la dignidad del ser humano. No todos los derechos sociales son fundamentales sino aquellos que, como la alimentación, el vestido, la vivienda, la educación o la sanidad, entre otros, permiten al ser humano las condiciones para una existencia en libertad solidaria"22.

Es insoslayable el paso de una noción donde el acento estaba puesto en el servicio mismo o su prestador, a una concepción donde el usuario (ser humano) es el protagonista del desarrollo de la figura, al punto de mutar la denominación clásica a la de "servicios de interés económico general"23. En el contexto actual, la "servicialidad" del Estado ha sido redescubierta, o al menos se manifiesta de manera muy distinta, y a la

20 PÉREZ HUALDE, Alejandro. Servicios Públicos, régimen, regulación y organismos de control. Servicios Públicos y Organismos de control; Lexis Nexis; Buenos Aires, p. 1-111, Año 2006.

21 LAPORTA, F.. Los derechos sociales y su protección jurídica: introducción al problema. En. BETEGON J. LAPORTA F. - DE PÁRAMO J.R. - PRIETO SANCHIS L. (Coordinadores), Constitución y derechos fundamentales, Revista del Centro de Estudios Constitucionales, N²2,Madrid, p. 298, 1995.

22 RODRIGUEZ ARANA MUÑOZ, Jaime. Sobre el concepto de los derechos sociales fundamentales. Revista Digital de la Asociación Argentina de Derecho Administrativo, Santa Fe, № 1, p. 10, ene/jun. 2016.

23 DURÁN MARTíNEZ, Augusto. Estado Constitucional de Derecho y servicios públicos. Revista de Direito Administrativo \& Constitucional. Año 15 № 60 , Editora Forum - Belo Horizonte (Brasil) -abril/junio 2015 -, p. 47. 
vez compleja. Digo redescubierta porque no es algo nuevo, al reposar en fundamentos ontológicos y teleológicos de indudable vigencia por provenir de la propia entidad del ser humano. Digo distinta, porque no se apunta primordialmente al carácter del prestador o a la naturaleza de los servicios prestados sino al destinatario, en virtud de que donde se crea un servicio para la colectividad es porque se ha detectado una necesidad a satisfacer, y esto porque subyace un derecho a esa satisfacción. Y digo compleja porque, atento las modificaciones operadas en la vida en sociedad, y las exigencias que ella impone para los ciudadanos, es evidente que en muchísimas situaciones la intervención del nivel primario de actuación (local) aparece como insuficiente para la cobertura eficaz del núcleo existencial comprometido. Insuficiencia a la que el principio de subsidiariedad aspira a erradicar en los casos concretos.

El hecho de que la mayoría de los derechos y obligaciones (tanto del prestador como del usuario) se encuentren plasmados en un contrato, no empece a considerar que muchas de esas prerrogativas integran la esfera de derechos fundamentales cuya protección no puede quedar sujeta únicamente a la fría letra de un instrumento privado. La obligación de prestar un servicio bajo ciertos parámetros de calidad, extensión territorial y tarifas accesibles tiene como correlato el respectivo derecho con iguales requerimientos. Esta noción conforma el derecho humano a un "mínimo de calidad de vida", derecho humano al que el servicio universal y solidario tiende a satisfacer. Cierto es que el contenido de éste variará en función del nivel de desarrollo social, económico y cultural de las poblaciones, pero esta falta de uniformidad no altera la idea básica sobre su morfología jurídica.

No es la intención de este trabajo ingresar en los factores económico-políticos que circundan la figura del servicio público en lo referente a los prestadores y las consecuentes modalidades de contratación. Si me permito hacer una breve referencia a la conexión que existe entre su implementación adecuada y otro principio estructural del Derecho Administrativo Global.

El derecho-deber a que el servicio se preste en condiciones de eficacia y eficiencia para el logro de las finalidades especìicas, está relacionado con el principio de buena administración, el que en su catalogación como derecho fundamental fue receptado expresamente por el Artículo 41 de la Carta de Derechos Fundamentales de la Unión Europea. El mentado principio, en este campo, se plasma en el derecho al buen funcionamiento de los servicios públicos, entendido como "funcionamiento acorde a las necesidades reales del hombre situado en un lugar y momento determinado".24

En los hechos, se trata ni más ni menos que de promover la generación de un marco normativo de aseguramiento de las garantías del usuario durante la negociación,

${ }^{24}$ DURÁN MARTíNEZ, A. La buena administración. Estudios de Derecho Administrativo, № 1. La Ley. Uruguay, p. $189,2010$. 
establecimiento de cláusulas y adhesión al contrato; además y durante la prestación del servicio, vigilar la protección de los estándares de calidad y continuidad del mismo; previendo consecuentemente los mecanismos de reclamo y restitución del servicio público en caso de incumplimiento.

\section{CONCLUSIÓN}

Conexidad multidimensional del servicio publico como derecho fundamental y verdadera política publica. El diseño de las técnicas y medidas en pos de la cobertura del núcleo mínimo, es un desafío que no puede ser encarado aisladamente por los Estados. Requiere programas y prácticas de campo con herramientas tecnológicas, recursos humanos, financiamiento interno y externo. Pero por sobre todo, decisiones políticas. Dejar de navegar en la intrascendencia de maniobras coyunturales e ir hacia lo profundo, hacia el meollo, avanzando por etapas, pero con la mirada en aquella progresividad plasmada en la Convención Americana de Derechos Humanos.

Hoy no es factible carecer de un sistema de gestión, con objetivos claros y preservando al ser humano en su integralidad, permitiéndole su desarrollo y el de generaciones futuras, en un entorno de participación, consenso, eficacia, conexidad metodológica y acuerdos intersectoriales.

Surgirán, seguramente, los escollos propios de las asimétricas realidades de los países. O prioridades basadas en el momento histórico. Lo cierto es que no hay facultades reservadas, exorbitancia, exclusividades o privilegios cuando se trata de alcanzar el mayor grado posible de desarrollo del ser por medio de la articulación en niveles, con la sencilla y contundente fuerza que los principios rectores de nuestro ordenamiento impulsan las renovaciones.

Fuerza es señalar, a través del análisis y comprensión de la normativa y esquemas conceptuales ensayados, que la instauración del servicio público bajo la forma que se trate, conlleva en nuestros tiempos la generación de vínculos de modalidades diversas atento el surgimiento de las figuras de usuario, consumidor, prestador, entes reguladores. Con la directriz marcada por el principio de igualdad y no discriminación, la naturaleza y el alcance de los derechos de unos, los deberes y obligaciones de otro, el rol del Estado en cuanto a la implementación, control, perfeccionamiento y desarrollo del instituto como parte de sus políticas activas de inclusión social, se modifican radicalmente, exigiéndose la participación activa de todos los sectores involucrados y un fluido intercambio de acciones por parte de los niveles endonacionales en el propósito de adaptar las normativas a los parámetros reconocidos y protegidos convencionalmente. Porqué allí reside, en mi opinión, una arista interesante: la responsabilidad del Estado en cuanto sus obligaciones de control y monitoreo sobre la actividad desarrollada por el prestador del servicio y la calidad de éste con relación al usuario. 
En esa tesitura, Tomás Fernández propugna una idea amplia de servicio público, como "...actividad cuyo cumplimiento debe ser asegurado, regulado y controlado por los gobernantes, porque el cumplimiento de dicha actividad es indispensable para la realización y desarrollo de la interdependencia social, y que es de tal naturaleza que no puede ser realizada completamente más que por la intervención de la fuerza gobernante, que por sí sola no prejuzga ningún régimen jurídico concreto"25.

Comprendiéndose la multiplicidad de aristas comprometidas en la problemática, y en aras una articulación coherente y realista entre Estado, Provincias y Municipios, armonizando las regulaciones y adaptándolas al marco imperante, la creación de unidades operativas en materia de servicios públicos con competencia determinada por normas especiales deviene trascendente.

La labor se presenta compleja porque, en la dinámica de funcionamiento del poder administrador, el cumplimiento de esos postulados viene de la mano de decisiones jurisdiccionales judiciales o de programas políticos ocasionales, con escaso o nulo compromiso del administrado, y cierto recelo por el supuesto peligro de desestabilización presupuestaria como efecto no buscado.

Se añade a ello que, la caracterización histórica del servicio público, comprensiva de su obligatoriedad, continuidad, regularidad, universalidad y uniformidad, se diseña y rediseña conforme los parámetros que cada Estado va trazando según las épocas, necesidades e involucrados, sin perder de vista que la titularidad de aquél trae aparejado un conjunto de relaciones que en los distintos niveles de prestación deben concertarse con la prioritaria finalidad de cobertura del núcleo mínimo.

Meilán Gil entiende que un derecho fundamental no podría ser contenido de la declaración de servicio público, aunque la concreción legislativa exhibe ejemplos numerosos de esa actitud. ${ }^{26}$, quizás en desmedro de la caracterización específica de la figura.

Ahora bien, en el Derecho Administrativo actual, con la dignidad de la persona humana como centro de protección y destinataria de las acciones consecuentes, tanto la declaración como la configuración, atribuciones y condiciones de prestación de un servicio público deben dirigirse, inexcusablemente, a la finalidad de garantizar el núcleo mínimo de los derechos fundamentales, noción difusa por la complejidad existente en los niveles donde se aprecian con mayor fuerza las deficiencias en aquél.

En el trayecto, se comprometen no sólo las labores de los organismos competentes, sino también el acercamiento del Estado al ciudadano para brindar mayor flexibilidad a la estructura del servicio, la propia actitud del usuario en su papel de colaboración para el mejoramiento, y el consenso con los eventuales prestadores, esto último en razón

25 FERNÁNDEZ, Tomás R.. Empresa Pública y Servicio Público: El final de una época. . Biblioteca Jurídica Virtual del Instituto de Investigaciones Jurídicas UNAM, México, p. 227, Año 1981.

26 MEILÁN GIL, José Luis. El servicio público en el derecho actual. Anuario da Facultade de Direito da Universidade da Coruña, La Coruña, España, Nº1, p. 383, 1997. 
de que el contenido económico que históricamente caracteriza al servicio público no podría, amén de su importancia, prevalecer ante el desconocimiento de las garantías ínsitas a la condición de persona.

\section{REFERENCIAS}

DURÁN MARTÍNEZ, Augusto. Estado Constitucional de Derecho y servicios públicos. Revista de Direito Administrativo \& Constitucional. Año 15 № 60 , Editora Forum - Belo Horizonte (Brasil), p. 39-62, abril/junio 2015.

DURÁN MARTÍNEZ, A. La buena administración. Estudios de Derecho Administrativo, № 1. La Ley. Uruguay, p. 189 y ss., 2010.

FERNÁNDEZ, Tomás R. Empresa Pública y Servicio Público: El final de una época. Biblioteca Jurídica Virtual del Instituto de Investigaciones Jurídicas UNAM, México, p. 213-228, Año 2011.

GONZÁLEZ MORAS, Juan M. El concepto de servicio público. Revista Argentina del Régimen de la Administración Pública, Buenos Aires, Año XXVI - 309, p. 185-222, Ediciones RAP SA, 2004.

GONZÁLEZ MORAS, Juan M. El concepto de servicio público en los Ordenamientos Públicos Globales. Revista Argentina del Régimen de la Administración Pública, Buenos Aires, № 361, p. 395-432, 2008.

IVANEGA, Miriam M. Urbanismo y Servicios Públicos. Biblioteca Jurídica Virtual del Instituto de Investigaciones Jurídicas UNAM, México, 2011, p. 201-221).

LAPORTA, F. Los derechos sociales y su protección jurídica: introducción al problema. En J. Betegon-F. Laporta-J.R. De Paramo-L. Prieto Sanchís (Coordinadores), Constitución y derechos fundamentales, Revista del Centro de Estudios Constitucionales, № 22,Madrid, p. 298, 1995.

Meilán Gil, José Luis. El servicio público en el derecho actual. Anuario da Facultade de Direito da Universidade da Coruña, La Coruña, España, № 01, p. 371-386, 1997.

PÉREZ HUALDE, Alejandro. Servicios Públicos, régimen, regulación y organismos de control. Servicios Públicos y Organismos de control; Lexis Nexis; Buenos Aires, p. 1-111, Año 2006.

RODRÍGUEZ-ARANA MUÑOZ, Jaime. Derecho Administrativo Español, Tomo I, México, Ed. Porrúa, 2005.

RODRÍGUEZ-ARANA MUÑOZ, Jaime. Sobre el concepto de los derechos sociales fundamentales. Revista Digital de la Asociación Argentina de Derecho Administrativo, Santa Fe, no 1, p. 07 -41 , ene/jun. 2016.

SCHIMDT-ASSMAN, Eberhard. La necesidad de la reforma en el derecho administrativo. En: Barnes, Javier (Editor) Innovación y reforma en el Derecho Administrativo, Madrid, p. 27-41, Editores INAP y Derecho Global, 2012.

VILLAR PALASI-VILLAR, Ezcurra. El ordenamiento jurídico administrativo. Principios de Derecho Administrativo, Madrid, Tomo I, P. 11-27 Editorial Universidad Complutense de Madrid, Facultad de Derecho, 1987 